\title{
AN EVALUATION OF RADIOSULFATE FOR THE DETERMINA- TION OF THE VOLUME OF EXTRACELLULAR FLUID IN MAN AND DOGS ${ }^{1}$
}

\author{
By MACKENZIE WALSER,2 DONALD W. SELDIN, AND ARTHUR GROLLMAN \\ (From the Departments of Internal Medicine and Experimental Medicine, Southwestern Medi- \\ cal School of The University of Texas, Dallas, Texas)
}

(Submitted for publication September 17, 1952 ; accepted December 24, 1952)

\section{INTRODUCTION}

Reasonably satisfactory methods have been developed for estimation of plasma volume (1) and total body water $(2,3)$ in normal subjects. On the other hand, no entirely satisfactory substance for estimating the volume of the extracellular fluid has as yet been found. It is not surprising that the material for this purpose should be more difficult to select, since, in order to have a volume of distribution equal to the extracellular fluid, it must be capable of passing through one membrane, the capillary wall, and yet be effectively excluded by the other, the cell wall.

The use of large molecules such as inulin $(4,5)$ and sucrose $(6,7)$, which are excluded for the most part from body cells, is restricted by their slow rate of capillary diffusion, particularly in the case of inulin, which generally necessitates a constant infusion and limits the applicability of these methods in edematous states (8). Mannitol, which diffuses more rapidly $(9,10)$, suffers from the disadvantage of changing extracellular fluid in two ways in the process of measuring it, because the plasma concentration required for accurate analysis exerts an effective osmotic pressure which draws water from cells, thereby expanding extracellular fluid volume, at the same time that a mannitol diuresis is sweeping sodium chloride into the urine.

Several ions which diffuse rapidly into the interstitial fluid have been employed for the measurement of extracellular volume, including bromide $(11,12)$, thiocyanate $(7)$, thiosulfate $(13,14)$, ferrocyanide $(15)$, and sulfate $(7,16)$. Bromide (17), thiocyanate $(7,18)$, and thiosulfate $(13)$ all penetrate cells to a significant extent. Thiosul-

1 This investigation was supported in part by a research grant from The National Institutes of Health, Public Health Service.

2 Present address: Naval Medical Research Institute, National Naval Medical Center, Bethesda, Maryland. fate, ferrocyanide, and sulfate suffer from the disadvantage of rapid urinary excretion which makes estimation of the amount remaining in the body at any given time subject to error. In addition, in the case of sulfate, correction for the amount normally present in plasma and urine is a further source of difficulty, while in the case of ferrocyanide, evidences of nephrotoxicity have been reported (19).

Radioactive labelling has made possible the use of sodium $(18,20-23)$ and chloride $(18,24,25)$. As is the case with bromide, these substances penetrate cells rapidly and at several different rates so that correction for the amount which has penetrated at any given time is difficult. A further disadvantage is their inconvenient half-life (14.8 hours for $\mathrm{Na}^{24}, 37$ minutes for $\mathrm{Cl}^{38}$, and $2 \times 10^{\circ}$ years for $\mathrm{Cl}^{36}$ ).

Sulfate labelled with $S^{35}$ has several theoretical advantages. Since the weight of sulfate injected is negligible (less than 5 micrograms), the serum concentration of sulfate is unaltered. Consequently, the rate of urinary loss remains sufficiently below the glomerular filtration rate to minimize errors induced by excessively rapid renal excretion, and yet is rapid enough so that little radioactivity remains in the blood after a few days. No correction for endogenous material is necessary, and, since the effective osmotic pressure of the extracellular fluid is unchanged, internal fluid exchanges are not altered. $\mathrm{S}^{35}$ has a convenient half-life of 87.1 days. The disappearance from the plasma of radiosulfate injected intravenously into normal human subjects, with observations as to the magnitude of the "radiosulfate space," has been presented in a preliminary report (26). This paper records further observations on the fate of radiosulfate in man and dogs, and an evaluation of its use as a substance with which to measure the volume of the extracellular fluid. 
The volume of distribution in water of the body of any foreign substance injected into the blood may be calculated as :

\section{Amount injected - amount excreted Concentration in interstitial water}

Where the substance is distributed at a uniform concentration throughout one phase of body fluids this calculation gives the actual volume of that phase, excluding the volume occupied by protein. As the substance penetrates into other phases of body fluids, its "volume of distribution" increases, but under these circumstances the calculated "volume" does not correspond to an actual volume of body fluid; nevertheless, it constitutes a useful measure of the amount of penetration which has occurred. After penetrating cells, a reference substance may also undergo metabolic transformation within the cell; here, too, the "volume of distribution" is an index of the amount of material which has been taken up, but not a measure of any anatomical fluid compartment. The use of the equation here employed affords by itself no information as to whether an increase in the volume of distribution is a consequence of penetration of the reference substance into cell water or to metabolic transformation as well.

The fate of radiosulfate injected intravenously has been studied, employing this equation. The data are divided into three sections: (1) the excretion of radiosulfate, (2) its disappearance from the blood, and (3) the result of combining these two values, the volume of distribution, as a function of time. Since the results in human subjects and dogs differ quantitatively but not qualitatively, they are presented concurrently.

\section{MATERIALS AND METHODS}

Carrier-free $\mathrm{S}^{\mathrm{w}}$, in the form of $\mathrm{H}_{2} \mathrm{SO}_{4}$, was obtained from the Oak Ridge National Laboratories on allocation by the Atomic Energy Commission. In order to prepare this material for injection, an appropriate volume was diluted with normal saline to give a concentration of 20 microcuries per $\mathrm{ml}$. After autoclaving, $5 \mathrm{ml}$. in a calibrated syringe were injected intravenously during the course of one minute. In the animal experiments, more concentrated solutions of $S^{25}$ were frequently used.

Two analytical methods were employed. The first involved the precipitation of sulfate as the benzidine salt from protein-free filtrates, and collection of the precipitate on filter paper by a suction apparatus (a modification of the procedure of Henriques and his coworkers [27]).
The second consisted of the direct determination of the radioactivity of serum and urine samples placed in stainless steel cups covered with aluminum foil (28). The former method measures only inorganic sulfate $S^{25}$; the latter measures total radioactivity. A flow counter was used for all analyses.

Inulin space was determined by the constant infusion technique (4), analyses being performed by the method of Roe, Epstein, and Goldstein (29).

The human subjects were normal physicians, medical students or nurses, and patients with psychiatric disturbances, rheumatoid arthritis or orthopedic disorders. None gave any evidence of renal disease or fluid retention. The dogs were trained mongrels, maintained on a meat diet with water, ad libitum.

Samples of urine were obtained without the use of catheters in all human subjects. High urine flows were found undesirable in the routine estimation of extracellular fluid (v.i.) but during the clearance determinations sufficiently rapid flows were maintained to minimize errors due to urinary dead space.

\section{RESULTS}

\section{The urinary excretion of radiosulfate}

$A$. The exchange of inorganic sulfate with organic sulfate. The radioactivity of urine was partitioned, in two experiments in normal men, between inorganic sulfate and organic sulfate. In the first, the activity of benzidine sulfate precipitates prepared before and after acid hydrolysis (30) of three urine samples during the first four hours after injection of radiosulfate was compared. Acid hydrolysis increased the activity less than 8 per cent. In the second experiment, the total radioactivity of three urine samples obtained during the first four hours, as determined by the liquid sample method, was compared with the radioactivity of benzidine sulfate precipitates. When corrected for the differences in sensitivity of the two methods, the results agreed within 5 per cent. It is concluded that the amount of administered radiosulfate excreted in an organic form within the first four hours after injection is negligible for the purpose of measuring its volume of distribution. Incorporation of radiosulfate into ethereal sulfate within 24 hours has been observed (31).

$B$. The proportion of the administered dose excreted during the period of equilibration. Evidence is presented below that equilibration of radiosulfate throughout the extracellular fluid requires 15 to 20 minutes in man and 20 to $30 \mathrm{~min}$ utes in dogs. Since the volume of distribution at 
these times is calculated as the amount remaining in the body divided by the concentration in interstitial fluid, an accurate estimate of the amount excreted is necessary. Collection of a complete urine sample over such a short period is extremely diffcult without a catheter, and the delay time from renal tubules to bladder makes quantitative recovery difficult even with catheterization. The proportion of the dose excreted may also be expected to vary in a single subject on successive occasions, due to variation in the amount of the injected material which circulates through the kidney during mixing.

In determinations on 15 normal human subjects the proportion of the administered dose voided 18 minutes after injection was measured. When urine flows were slow, a long period without voiding preceded the injection so that collection might be as complete as possible. The proportion of the administered dose recovered varied from 1.3 per cent to 8.8 per cent, averaging 4.5 per cent. The variation in a single individual was as great as for the entire group. No correlation with urine flow was noted.

In six normal dogs, urine samples were obtained by catheter 25 to 30 minutes after injection, and the bladder was washed several times with distilled water. These animals were not loaded with water prior to the experiment. The proportion of the administered dose which was recovered varied from 1.0 per cent to 6.0 per cent, averaging 3.6 per cent. In another group of six normal dogs, water loading by stomach tube was begun one hour before the injection of radiosulfate. The proportion of the dose collected by catheter within 25 to 30 minutes varied from 3.7 per cent to 8.2 per cent, averaging 5.6 per cent.

An attempt was made to determine whether more consistent values for the volume of distribution of radiosulfate could be obtained by determining the amount excreted in the urine or by assuming that a constant fraction, for example 5 per cent, was always lost during equilibration. In duplicate determinations of the radiosulfate volume of distribution measured at intervals of several days in six normal human subjects, the average difference between paired sulfate spaces was 0.16 liter when the measured radiosulfate excretion into the urine was taken into account and 0.30 liter when it was assumed that a constant fraction was excreted. In eight normal dogs, the variability of extracellular fluid volume per unit of body weight or surface area was slightly greater when a constant fraction of the dose was assumed to have been excreted than when the amount recovered from catheterized urine specimens was used in the calculation.

In conclusion it appears that 4 to 8 per cent of an administered dose of radiosulfate is excreted during equilibration, although as little as 1 per cent may be collected from the bladder when the rate of urine flow is low (presumably because of urinary dead-space errors). Omission of urine collection and the assumption of an average fraction lost therefore entails a small error in normal human subjects and dogs. Where sulfate clearance is abnormal, collection of urine is obviously mandatory.

C. The clearance of radiosulfate in normal subjects. Using one to five 20 to 60 minute clearance periods, the clearance of radiosulfate following a single injection was calculated in six normal human subjects (Table I).

TABLE I

The clearance of radiosulfate in normal subjects

\begin{tabular}{lcc}
\hline \hline Subject & Clearance & Clearance \\
\hline & cc./min. & cc./min./1.73 sq. M. \\
J. N. & 34 & 37 \\
A. H. & 31 & 36 \\
M. W. & 37 & 34 \\
J. J. & 49 & 33 \\
S. B. N. & 24 & 33 \\
S. S. & 38 & 39 \\
& & Average 35 \\
\hline
\end{tabular}

The clearance did not tend to change progressively during the interval from 18 minutes after injection to three hours after injection. For example, the clearance in subject $M$. W. on successive 40 minute periods was $38.1,35.3,37.2$, and $37.2 \mathrm{cc}$. per minute; in subject S. S. three successive 60 minute periods gave clearances of 38.8, 36.9 , and $39.1 \mathrm{cc}$. per minute. Evidently exogenous sulfate is cleared at the same rate by the kidney after 18 minutes, for a period of at least three hours. If some radiosulfate became bound to protein, as Bjering and $\emptyset$ llgaard (32) assert that a portion of the plasma sulfate is, the clearance would change. 
The mean value of $35 \mathrm{cc}$. per minute per $1.73 \mathrm{sq}$. meters is in accord with previous values (not related to surface area) of $37.3 \mathrm{cc}$. per minute (32), $35.5 \mathrm{cc}$. per minute (33), and $35 \mathrm{cc}$. per minute (34) for endogenous sulfate clearance in normal human subjects. Determinations of simultaneous endogenous sulfate clearances were not available in our subjects. The close agreement suggests that exogenous radiosulfate is cleared in the same manner as endogenous sulfate, and further supports the accepted view (35) that all of the plasma inorganic sulfate is filtrable through the glomerulus.

D. Cumulative urinary excretion. The total amount of radioactivity excreted in the urine at intervals after injection was measured in five normal human subjects and five normal dogs. Figures 1 and 2 show the results, which have been plotted as the fraction of the dose remaining in the body on a logarithmic scale against time. The curves for all the dogs and all of the human subjects except J.G. are linear. The failure of the extrapolated lines to intersect the origin is a consequence of the greater urinary loss during the period of equilibration. The half-time of urinary excretion varies from 228 minutes to 522 minutes for the human subjects (average 354 minutes or 5.9 hours) and



Fig. 1. Cumulattve Urinary Excretion of Radiosulfate in Normal Human Subjects, Plotted as Per Cent Remaining on a Logarithmic Scale Against Time

The curves are linear in all subjects except $J$. G. The average time required for excretion of half of the dose is $\mathbf{5 . 9}$ hours.



Fig. 2. Cumulative Urinary Excretion of Radiosulfate in Normal Dogs

Dog 9 has been excluded because of loss of part of the first urine sample. The average half-time is $\mathbf{7 . 5}$ hours. For interpretation of the extrapolated lines, see text. 


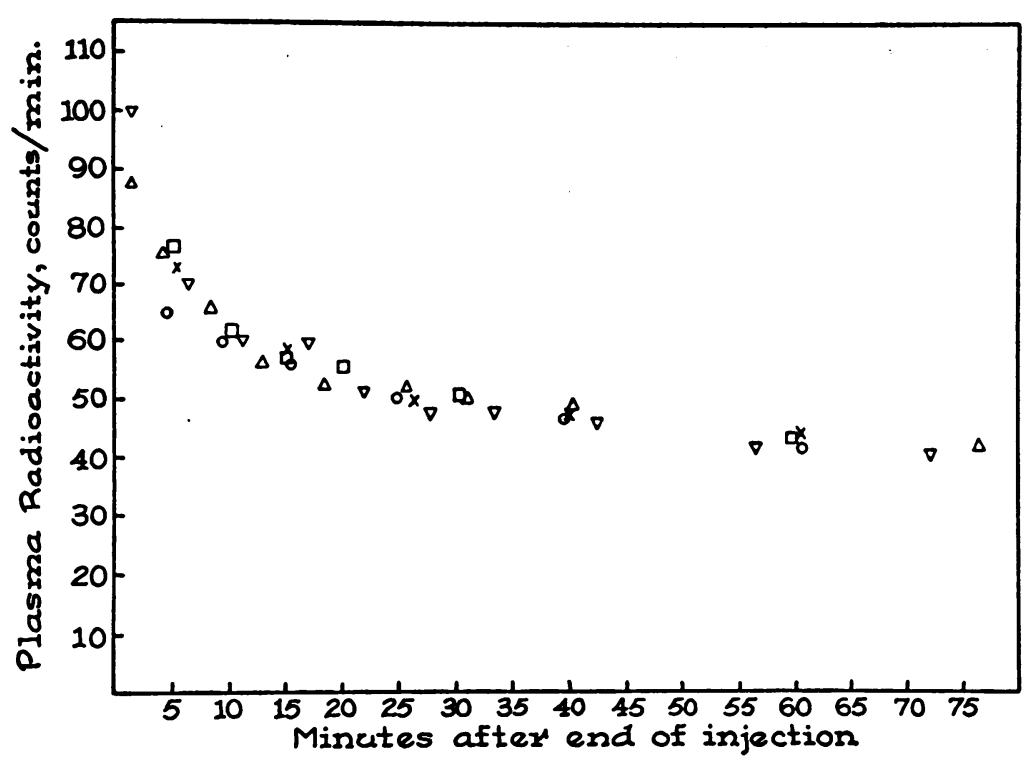

Fig. 3. A Composite Curve of Disappearance from the Serum of RadioSulfate in Five Normal Dogs

All values obtained before 30 minutes are from arterial samples. For each animal (represented by a single symbol), the curves have been adjusted by appropriate factors to make the doses comparable. (Actual counts recorded were 10 times the values given in the figure.)

324 minutes to 510 minutes for the dogs (average 450 minutes or 7.5 hours).

\section{Disappearance of radiosulfate from the blood}

In a previous report (26) the disappearance of serum radioactivity for normal human subjects during the first hour after injection of radioactive sulfur was presented. A "break" was evident at 15 to 20 minutes. The differences between the observed arterial concentrations during the first 15 minutes and the later slow rate of disappearance extrapolated back to the origin were found to decrease at a single exponential rate with a half-time of 2.5 minutes (decay constant 0.28 ) in four normal subjects.

The falling curves of arterial serum radioactivity in five normal dogs are shown in Figure 3 (an arteriovenous difference could not be detected after 20 minutes; consequently venous samples were used in determining most of the later points). The "break" appears to occur at 25 to 30 minutes. The differences between the extrapolated later slow rate of disappearance and the observed arterial concentration during the first 20 minutes were calculated in four dogs. When results are plotted semilogarithmically straight lines are obtained in all four animals, with a half-time of four minutes in three and 2.2 minutes in the fourth animal (Figure 4). In all four animals, therefore, the "excess" plasma activity has fallen to 1 per cent or less of its initial value within 25 minutes. The other dog included in Figure 3 is omitted because an insufficient number of early arterial samples were obtained for this type of analysis.

In the three normal human subjects who remained recumbent and fasting for several hours the subsequent disappearance of radiosulfate from the venous serum was observed. The subjects ingested half a glass of water every half hour. The first sample was obtained 18 minutes after the end of injection. When serum radioactivity is plotted on a logarithmic scale against time straight lines are obtained for all three subjects (Figure 5).

In six normal dogs, similar data were obtained (Figure 6). The dogs were kept on an animal board, fasting, throughout the procedure, with the exception of dogs 9 and 10, which were removed from the board and allowed to walk about the laboratory after the times noted by arrows on the figure. Straight lines are obtained for all the animals with the exception of dog 10. The sharp 




Fig. 4. Equilibration of Radiosulfate in Four Dogs

The difference between the observed arterial serum radioactivity and the later slow rate of disappearance (extrapolated to zero time) is plotted on a logarithmic scale against time. Straight lines were drawn visually for each animal (two are superimposed). The half-times are 2.2 minutes in one animal and four minutes in the other three. (Actual counts recorded were 10 times the values given in the figure.)

change in slope observed in this animal, coinciding with the point at which it assumed an upright position, may have been due to a change in glomerular filtration rate, although no such change in slope occurred in dog 9 .

It is concluded that the disappearance of radiosulfate from the blood after intravenous injection in one minute can be described by two additive single exponential rates, an initial rapid one which is essentially completed in 18 to 20 minutes in man and 25 to 30 minutes in dogs, and a slow rate which remains unchanged thereafter, for at least several hours.

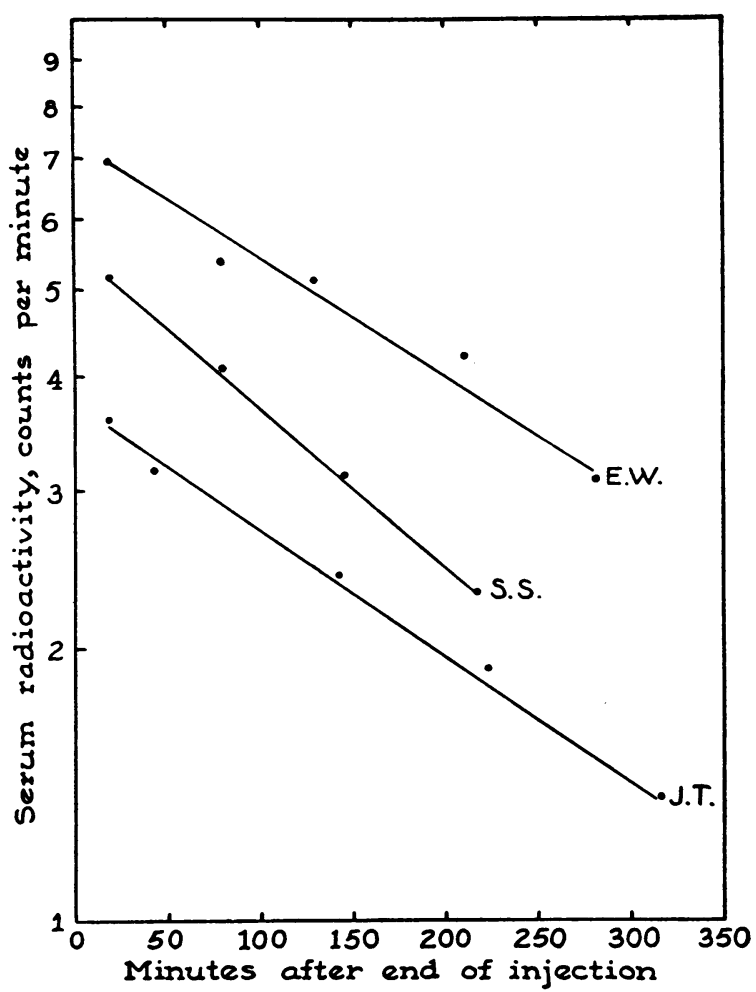

Fig. 5. The Disappearance of Radiosulfate from the Blood, in Normal Human Subjects, During the First Three to Five Hours

Radioactivity is plotted on a logarithmic scale against time. The curves are linear from 18 minutes on in each subject. (Actual counts recorded were 64 times values given in the figure.)

\section{The volume of distribution of radiosulfate as a function of time}

The volume of distribution of radiosulfate was estimated at intervals from the formula:

\section{Amount injected - amount excreted Concentration in interstitial water}

In order to determine the concentration in interstitial water, it is necessary to correct the observed serum radioactivity for serum water content and the Donnan factor. In some of the normal human subjects serum water content was determined as the difference between wet and dry weight of serum. In most of the human subjects, however, and in all of the dogs, a normal serum water content of 93 per cent was assumed. The Donnan factor for sulfate was assumed to be the square of that for chloride $(0.95)$, or 0.90 . Pre- 


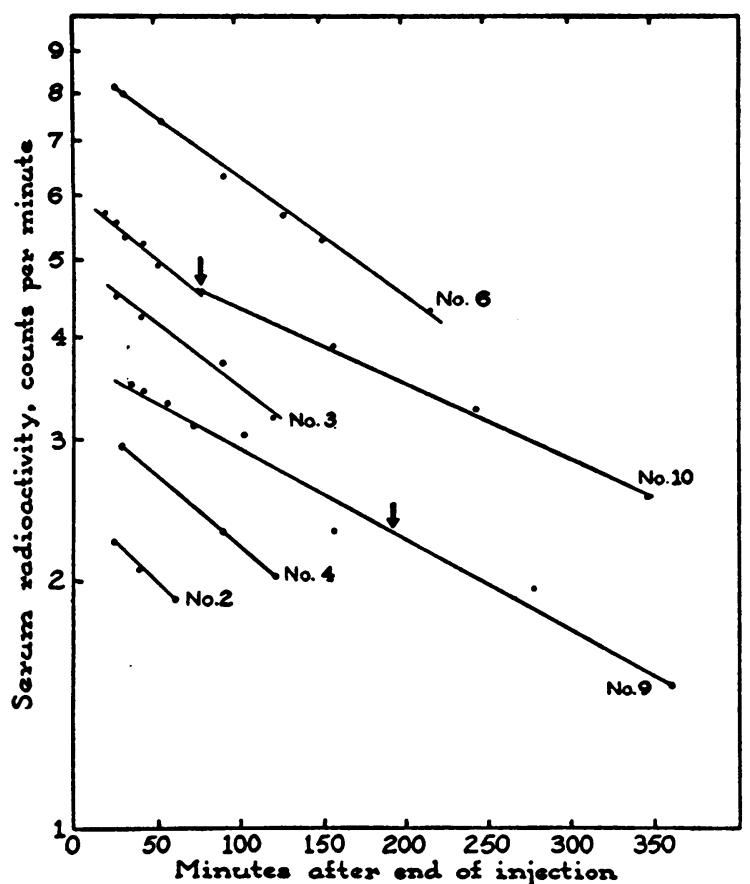

Fig. 6. The Disappearance of Radiosulfate from the Blood in Normal Dogs

Radioactivity is plotted on a logarithmic scale against time. Dogs 9 and 10 were removed from the animal board at the times indicated by arrows. Linear plots are obtained for all the animals. (Actual counts recorded were 64 times values given in the figure.)

vious studies have shown that all of plasma sulfate is ultrafiltrable $(36-38)$.

The volume of distribution at intervals following injection was determined in four normal human subjects and six normal dogs. For both species the increase in volume of distribution with time appears to be linear (Figures 7 and 8). The rate of increase was calculated for each subject. In the human subjects it varied from 1.75 per cent to 3.13 per cent of body weight per hour, averaging 2.18 per cent. In the dogs it varied from 1.35 per cent to 3.93 per cent of body weight per hour, averaging 2.66 per cent.

The exponential rate of disappearance of radiosulfate from the blood exceeds the exponential rate of urinary loss, indicating that the former rate represents the summation of loss by excretion and another single exponential rate of disappearance elsewhere. Calculation of the rates reveals that the fraction of the amount remaining which disappears from the blood per unit time is, in fact, about twice as great as the fraction which appears in the urine. Under these circumstances the volume of distribution should increase exponentially rather than linearly. ${ }^{3}$ The data do not permit a definite conclusion as to whether the increase is, in fact, exponential or linear. However, if these same linear rates of increase obtained during the period of equilibration, values for the volume of distribution at 18 minutes in man would be 0.65 per cent of body weight greater than if equilibration had occurred instantaneously and values for the volume of distribution at 30 minutes in dogs would be 1.33 per cent greater. But since the interstitial fluid, from which the radiosulfate must enter body cells, contains substantially less radiosulfate during this period than it does thereafter, the fraction which penetrates during this interval will be somewhat less than in a subsequent interval of equal duration. The error due to cellular penetration during equilibration is thus about 0.5 per cent of body weight in man and about 1 per cent of body weight in dogs.

\section{The magnitude of the radiosulfate space in normal humans and dogs}

The volumes of distribution of radiosulfate 18 minutes after injection in 18 normal men and women are presented in Table II." All determinations were made in fasting subjects, who had been ingesting salt ad libitum. Neither coffee nor alcohol was taken on the evening before, and water was not forced. In earlier observations when several glasses of water were ingested shortly before the

${ }^{3}$ Let $V_{D_{\mathbf{t}}}=$ volume of distribution at time $t$,

IV = amount injected,

$U V_{t}=$ total amount excreted at time $t_{\text {, }}$

$\mathbf{C}_{\mathbf{t}}=$ plasma concentration at time $t$,

$C_{0}=$ extrapolated plasma concentration at $t_{0}$,

$k_{p}=$ exponential rate of disappearance from the plasma,

$k_{u}=$ exponential rate of urinary loss.

The data indicate that, after 18 to 30 minutes:

$$
I V-U V_{t}=I V e^{-k_{n} t} \text {, and } C_{t}=C_{0} e^{-k_{p} t} \text {. }
$$

Since, by definition,

Therefore,

$$
V_{D_{t}}=\frac{I V-U V_{t}}{C_{t}},
$$

$$
V_{D_{t}}=\frac{I V e^{-k_{u} t}}{C_{0} e^{-k_{p} t}}=\frac{I V}{C_{0}} e^{\left(k_{p}-k_{u}\right) t} .
$$

4 Part of these observations were obtained through the courtesy of Dr. Alvin Shapiro. 


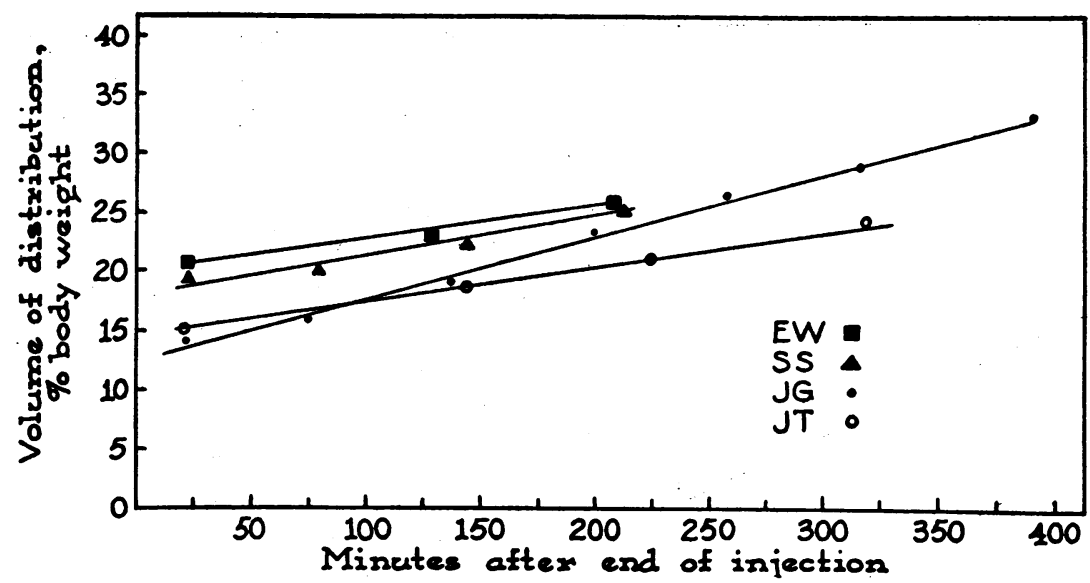

Fig. 7. The Apparent Volume of Distribution of Radrosulfate at Intervals after Injection in Four Normal Human Subjects

The results for subject $M$. W. are included in a previous report (26).

The rate of increase appears to be constant in each subject, and averages 2.1 per cent of body weight per hour.

injection of radiosulfate, the volume of distribution appeared to increase (as compared to previous determinations in the same subject) more than if the water were distributed throughout total body water, probably due to the relatively slow rate at which administered water equilibrates with cell water (2). A constant fraction of the administered dose, 4 per cent, was assumed to have been excreted during the first 18 minutes and collection of urine was omitted. The average value in these subjects expressed as per cent of body weight is 14.6 per cent, with a range of 11.5 per cent to 20.9 per cent. Relating the values to surface area rather than body weight evidently did not decrease the variability; the mean is 5.5 liters per sq. meter. Combining the previous series of 10 subjects (26) and these 18 subjects, an average value of 15.1 per cent of body weight is obtained.



Fig. 8. The Apparent Voluye of Distribution of Radiosulfate at Intervals after Injection in Six Norkal Dogs

In $\operatorname{dog} 9$ a value for the fraction of the dose excreted during the first $\mathbf{3 0}$ minutes has been assumed. The rate of increase is nearly constant in each animal. It averages 2.66 per cent of body weight per hour. 
TABLE II

The volume of distribution at 18 minutes of radiosulfate in normal human subjects

\begin{tabular}{|c|c|c|c|c|c|c|c|c|}
\hline Subject & Age & Sex & Height & Weight & $\begin{array}{c}\text { Surface } \\
\text { area }\end{array}$ & Volume & Volume & Volume \\
\hline \multirow[t]{2}{*}{$\begin{array}{l}\text { G. F. } \\
\text { G. H. } \\
\text { J. G. } \\
\text { L. G. } \\
\text { S. S. } \\
\text { S. C. } \\
\text { J. J. } \\
\text { R. T. } \\
\text { A. P. } \\
\text { I. D. } \\
\text { E. V. } \\
\text { J. P. } \\
\text { E. W. } \\
\text { D. S. } \\
\text { D. V. } \\
\text { A. S. } \\
\text { J. T. } \\
\text { L. S. }\end{array}$} & $\begin{array}{l}16 \\
46 \\
40 \\
44 \\
48 \\
28 \\
33 \\
45 \\
47 \\
28 \\
42 \\
62 \\
35 \\
31 \\
27 \\
31 \\
42 \\
44\end{array}$ & $\begin{array}{l}\mathbf{F} \\
\mathbf{M} \\
\mathbf{F} \\
\mathbf{M} \\
\mathbf{F} \\
\mathbf{F} \\
\mathbf{M} \\
\mathbf{F} \\
\mathbf{F} \\
\mathbf{F} \\
\mathbf{M} \\
\mathbf{M} \\
\mathbf{M} \\
\mathbf{M} \\
\mathbf{M} \\
\mathbf{M} \\
\mathbf{M}\end{array}$ & $\begin{array}{l}c m . \\
155 \\
161 \\
160 \\
166 \\
170 \\
166 \\
171 \\
173 \\
161 \\
168 \\
163 \\
156 \\
178 \\
180 \\
179 \\
176 \\
180 \\
172\end{array}$ & $\begin{array}{c}K_{8 .} \\
42.3 \\
55.8 \\
63.7 \\
59.4 \\
59.0 \\
62.2 \\
60.7 \\
59.0 \\
65.9 \\
66.2 \\
69.8 \\
68.7 \\
69.4 \\
68.2 \\
70.8 \\
77.4 \\
75.1 \\
97.6\end{array}$ & $\begin{array}{l}\text { sq. M. } \\
1.36 \\
1.57 \\
1.65 \\
1.66 \\
1.68 \\
1.69 \\
1.69 \\
1.70 \\
1.70 \\
1.74 \\
1.76 \\
1.81 \\
1.86 \\
1.87 \\
1.89 \\
1.94 \\
1.95 \\
2.11\end{array}$ & \begin{tabular}{r}
\multicolumn{1}{c}{$\boldsymbol{L}}$. \\
5.2 \\
7.6 \\
9.1 \\
9.3 \\
9.2 \\
7.9 \\
8.1 \\
10.6 \\
7.6 \\
8.1 \\
14.6 \\
9.7 \\
14.1 \\
9.1 \\
10.5 \\
9.7 \\
12.5 \\
11.2
\end{tabular} & $\begin{array}{l}\% \text { wt. } \\
12.3 \\
13.6 \\
14.3 \\
15.6 \\
15.6 \\
12.7 \\
13.3 \\
18.0 \\
11.5 \\
12.2 \\
20.9 \\
14.1 \\
20.3 \\
13.3 \\
14.8 \\
12.5 \\
16.6 \\
11.5\end{array}$ & $\begin{array}{c}\text { L./sq. M. } \\
3.8 \\
4.8 \\
5.5 \\
5.6 \\
5.5 \\
4.7 \\
4.8 \\
6.2 \\
4.5 \\
4.6 \\
8.3 \\
5.3 \\
7.6 \\
4.9 \\
5.6 \\
5.0 \\
6.4 \\
5.3\end{array}$ \\
\hline & & & & & & ard devi & $\begin{array}{r}14.6 \\
2.7\end{array}$ & $\begin{array}{l}5.5 \\
1.1\end{array}$ \\
\hline
\end{tabular}

The volumes of distribution of radiosulfate 25 to 30 minutes after injection in 16 normal dogs are listed in Table III. Urine was collected by catheter, and the bladder was washed with water. The mean of 20.1 per cent of body weight corresponds closely to estimates made by other methods (39). The higher value obtained in these animals and the greater constancy than in man are presumably due to the small proportion of their body weight which is fat.

TABLE III

The volume of distribution at 25 to 30 minutes of radiosulfate in normal dogs

\begin{tabular}{lcc}
\hline \hline Wt. & Volume & Volume \\
\hline$K_{g .}$ & $c c$. & \% body wot. \\
5.92 & 1,385 & 23.4 \\
6.41 & 1,124 & 17.5 \\
8.52 & 1,663 & 19.5 \\
8.70 & 1,870 & 21.5 \\
9.18 & 2,040 & 22.2 \\
9.30 & 1,920 & 20.6 \\
9.40 & 2,000 & 21.3 \\
10.36 & 1,782 & 17.2 \\
11.02 & 2,072 & 18.8 \\
11.34 & 2,257 & 19.9 \\
11.79 & 2,464 & 20.9 \\
13.61 & 2,164 & 15.9 \\
14.24 & 3,070 & 21.6 \\
16.15 & 2,875 & 17.8 \\
18.90 & 4,270 & 22.6 \\
19.14 & 4,239 & 22.1 \\
& & 20.1 \\
& Standard deviation & 2.1 \\
& & Mean
\end{tabular}

TABLE IV

Comparison of simultaneous inulin and radiosulfate spaces in man

\begin{tabular}{cccc}
\hline \hline Subject & Inulin & $\begin{array}{c}\text { Radio- } \\
\text { sulfate } \\
\text { space }\end{array}$ & $\begin{array}{c}\text { Ratio } \\
\text { radiosulfate } \\
\text { space : inulin } \\
\text { space }\end{array}$ \\
\hline & space & $L$. & \\
1 & $L$. & 12.8 & 1.07 \\
2 & 12.0 & 13.9 & 0.97 \\
3 & 14.4 & 9.3 & 1.00 \\
4 & 9.3 & 9.5 & 0.80 \\
5 & 11.9 & 12.7 & 1.15 \\
6 & 11.0 & 12.6 & 0.91 \\
7 & 13.8 & 12.2 & 0.84 \\
8 & 14.5 & 8.8 & 0.88 \\
9 & 10.0 & 9.1 & 0.93 \\
& 9.8 & & Mean \\
& & & 0.95 \\
& & Standard deviation & 0.11 \\
\hline
\end{tabular}

$V$. Comparison of simultaneous radiosulfate and inulin spaces

Inulin space was determined by urine collection for 17 to 19 hours following a priming dose and a constant infusion for five to six hours (4) in nine human subjects. The concentrations of inulin in the serum were corrected for a serum water content of 93 per cent. Radiosulfate space was determined during the infusion. The results are shown in Table IV. The ratio of radiosulfate space to inulin space varies from 0.80 to 1.15 , averaging 0.95 . 


\section{DISCUSSION}

In evaluating any procedure for measuring a fluid space in the body it is necessary to define the anatomical extent of the space in question. The term "extracellular fluid" may be construed in a strict sense to include all body water which is not actually within cell membranes. However, anatomical and functional subdivisions of this water can be distinguished. One distinct subdivision is the water in the gastrointestinal tract, glandular lumina, urine remaining in the upper and lower urinary tract, and other portions of body water which are, in a sense, outside of the body. The term "transcellular water" has been proposed recently to distinguish these areas (40). Another subdivision, which is as yet poorly defined, is that portion of the extracellular fluid which does not appear to be in diffusion equilibrium with the rest, and, at least in experiments of short duration, acts as though it were intracellular. Connective tissue water is the chief example of this "non-functional extracellular fluid." The difficulty in defining the extent of this fluid space lies in determining at what point it ends and true intracellular water begins.

It is evident that the inclusion of "transcellular water" and "non-functional extracellular fluid" is undesirable in a measure which has as its purpose the estimation of that portion of chloride-containing body fluid which is responsive to acute changes in the composition of the plasma. On the other hand, for the purpose of estimating changes in intracellular composition from external balances of electrolytes by the difference between total body content and extracellular fluid content, it may be desirable to include "non-functional extracellular fluid," since its composition may eventually respond to changes in the more readily diffusible portion, and perhaps "transcellular water" as well, since the latter is included in total body water measurements (40).

It appears that radiosulfate space does not include either of these subdivisions of extracellular fluid. The low concentrations found in gastric juice and stool relative to the blood (41) suggest that only small amounts of "transcellular water" are included. The similarity of radiosulfate space to the dilution volumes of inulin, sucrose, and ferrocyanide, molecules of widely varying size, is evidence that these substances all measure the same physiologically distinct compartment of body water, which may be termed the "functional extracellular fluid."

All of these substances, therefore, may be used to estimate the volume of body fluid throughout which an acute change in plasma composition is reflected, but in long balance studies the calculated change in the electrolyte composition of the remainder of body water may involve not only body cells but also the non-functional extracellular fluid.

From comparisons of total body chloride content (determined by carcass analysis [42], dilution of labelled chloride [24], or bromide space $[17,43-45]$ ) with the volume of distribution of inulin, it has been concluded $(24,45,46)$ that from one-fourth to one-half of the total body chloride is outside of the functional extracellular fluid, i.e., is not in diffusion equilibrium with the rest. Obviously, chloride balance need not parallel extracellular fluid volume changes in long-term studies, although in acute studies it may do so accurately.

The site and nature of this relatively indiffusible chloride has been sought by determinations of the fraction of tissue chloride space which fails to respond to induced changes in the composition of the extracellular fluid (47-50), and by comparisons of the tissue chloride space with the tissue space of other referent substances (51-55). These studies have shown that varying portions of the chloride space, notably in connective tissue, are impenetrable to sulfate $(47,55)$, thiosulfate $(51)$, and inulin (51-54). Radiosulfate also fails to penetrate about 25 per cent of the chloride space of muscle (41). The moiety of muscle chloride space which is unpenetrated may be almost entirely due to its connective tissue content (51).

It is evident, therefore, that these substances measure only a portion of the extracellular fluids of the body, but, for many purposes, the most important portion.

The data presented do not show definitely whether the progressive extrarenal loss of radiosulfate after equilibration represents cellular penetration (with or without metabolism of sulfate as well), or gradual diffusion into the non-functional extracellular fluid. However, the exponential decline in the plasma concentration towards zero, even when the rate of urinary loss is subtracted, indicates that after 15 to 30 minutes radiosulfate is slowly lost into areas from which it does 
not return in measurable amounts. If the phase into which it is penetrating were a more remote portion of the extracellular fluid which is nevertheless in diffusion equilibrium with the rest, it would be expected that detectable amounts of radiosulfate would diffuse back. Since this is not the case, it is tentatively concluded that the progressive increase in the apparent volume of distribution reflects progressive cellular penetration and/or metabolism, and that if radiosulfate gains access to the non-functional extracellular fluid at all, it does so very slowly.

The variability of radiosulfate space per unit weight in the human subjects is not surprising, in view of the wide variation in body fat content (5661). Total body water has been shown to be a very constant proportion of "fat-free" weight in man (59). Similar observations have been made for muscle (61). Since body water may vary from 30 per cent to 68 per cent of body weight (46), it is not surprising that extracellular fluid volume should vary to the same degree. The surface area correction, as obtained from standard tables, does not remove this variability since it is unaffected by the proportion of fat and lean tissue in an individual of any given height or weight.

\section{SUMMARY AND CONCLUSION}

Radiosulfate is shown to be a satisfactory and convenient measure of the functional extracellular fluid volume in normal man and dogs, on the basis of the following observations:

1. Diffusion equilibrium after a single injection is achieved in 15 to 20 minutes in man and 20 to 30 minutes in dogs.

2. Only 4 to 8 per cent of the dose is excreted during equilibration, so that urine collection may be omitted without serious error.

3. Cellular penetration during equilibration is slight in both species, but greater in dogs than in man.

4. Half of the dose is excreted within four to nine hours, so that frequent determinations can be made.

5. Repeated determinations in a single individual differ by an average of 0.16 to 0.30 liter.

6. The ratio of radiosulfate space to simultaneously determined inulin space in nine human subjects was $0.95 \pm 0.11$.
7. The radiosulfate space in 28 normal men and women was 11 per cent to 21 per cent of body weight, averaging 15.1 per cent in this series. In 16 normal dogs it was $20.1 \pm 2.1$ per cent of body weight.

Evidence in support of the accepted view that all of the plasma sulfate is filtrable through the glomerulus is also presented.

\section{ACKNOWLEDGMENT}

We are indebted to Marion Morgan, Gordon Gafford, and Helen Johnson for technical assistance.

\section{REFERENCES}

1. Gibson, J. G., 2nd, and Evans, W. A., Jr., Clinical studies of the blood volume. I. Clinical application of a method employing the blue azo dye "Evans Blue" and the spectrophotometer. J. Clin. Invest., 1937, 16, 301.

2. Schloerb, P. R., Friis-Hansen, B. J., Edelman, I. S., Solomon, A. K., and Moore, F. D., The measurement of total body water in the human subject by deuterium oxide dilution with a consideration of the dynamics of deuterium distribution. J. Clin. Invest., 1950, 29, 1296.

3. Soberman, R., Brodie, B. B., Levy, B. B., Axelrod, J., Hollander, V., and Steele, J. M., The use of antipyrine in the measurement of total body water in man. J. Biol. Chem., 1949, 179, 31.

4. Schwartz, I. L., Schachter, D., and Freinkel, N., The measurement of extracellular fluid in man by means of a constant infusion technique. J. Clin. Invest., 1949, 28, 1117.

5. Gaudino, M., and Levitt, M. F., Inulin space as a measure of extracellular fluid. Am. J. Physiol., 1949, 157, 387.

6. Deane, N., Schreiner, G. E., and Robertson, J. S., The velocity of distribution of sucrose between plasma and interstitial fluid, with reference to the use of sucrose for the measurement of extracellular fluid in man. J. Clin. Invest., 1951, 30, 1463.

7. Lavietes, P. H., Bourdillon, J., and Klinghoffer, K. A., The volume of the extracellular fluids of the body. J. Clin. Invest., 1936, 15, 261.

8. Last, J. H., McDonald, G. O., Jones, R. A., and Bond, E. E., Rates of equilibration of inulin and mannitol between plasma and interstitial water in edematous states. J. Lab. \& Clin. Med., 1952, 39, 62.

9. Newman, E. V., Bordley, J., III, and Winternitz, J., The interrelationships of glomerular filtration rate (mannitol clearance), extracellular fluid volume, surface area of the body and plasma concentration of mannitol. A definition of extracellular fluid clearance determined by following plasma concentration after a single injection of mannitol. Bull. Johns Hopkins Hosp., 1944, 75, 253. 
10. Elkinton, J. R., The volume of distribution of mannitol as a measure of the volume of extracellular fluid, with a study of the mannitol method. J. Clin. Invest., 1947, 26, 1088.

11. Wallace, G. B., and Brodie, B. B., The distribution of administered bromide in comparison with chloride and its relation to body fluids. J. Pharmacol. \& Exper. Therap., 1939, 65, 214.

12. Brodie, B. B., Brand, E., and Leshin, S., The use of bromide as a measure of extracellular fluid. $\mathrm{J}$. Biol. Chem., 1939, 130, 555.

13. Gilman, A., Philips, F. S., and Koelle, E. S., The renal clearance of thiosulfate with observations on its volume distribution. Am. J. Physiol., 1946, 146, 348.

14. Cardozo, R. H., and Edelman, I. S., The volume of distribution of sodium thiosulfate as a measure of the extracellular fluid space. J. Clin. Invest., 1952, 31, 280.

15. Calcagno, P. L., Husson, G. S., and Rubin, M. I., Measurement of "extracellular fluid space" in infants by equilibration technic using inulin and sodium ferrocyanide. Proc. Soc. Exper. Biol. \& Med., 1951, 77, 309.

16. Bourdillon, J., and Lavietes, P. H., Observations on the fate of sodium sulfate injected intravenously in man. J. Clin. Invest., 1936, 15, 301.

17. Berger, E. Y., Dunning, M. F., Steele, J. M., Jackenthal, R., and Brodie, B. B., Estimation of intracellular water in man. Am. J. Physiol., 1950, 162, 318.

18. Winkler, A. W., Elkinton, J. R., and Eisenman, A. J., Comparison of sulfocyanate with radioactive chloride and sodium in the measurement of extracellular fluid. Am. J. Physiol., 1943, 139, 239.

19. Miller, B. F., and Winkler, A., The ferrocyanide clearance in man. J. Clin. Invest., 1936, 15, 489.

20. Kaltreider, N. L., Meneely, G. R., Allen, J. R., and Bale, W. F., Determination of the volume of the extracellular fluid of the body with radioactive sodium. J. Exper. Med., 1941, 74, 569.

21. Manery, J. F., and Bale, W. F., The penetration of radioactive sodium and phosphorus into the extraand intracellular phases of tissues. Am. J. Physiol., 1941, 132, 215.

22. Aikawa, J. K., Fluid volumes and electrolyte concentrations in normal rabbits. Am. J. Physiol., 1950, 162, 695.

23. Levitt, M. F., and Gaudino, M., Use of radioactive isotopes to measure intracellular cation concentrations in the normal dog. Am. J. Physiol., 1949, 159, 67.

24. Burch, G. E., Threefoot, S. A., and Ray, C. T., Rates of turnover and biologic decay of chloride and chloride space in the dog determined with the longlife isotope, $\mathrm{Cl}^{\star *}$. J. Lab. \& Clin. Med., 1950, 35, 331.

25. Manery, J. F., and Haege, L. F., The extent to which radioactive chloride penetrates tissues, and its significance. Am. J. Physiol., 1941, 134, 83.
26. Walser, M., Volume of distribution of radiosulfate as a measure of the extracellular fluid. Proc. Soc. Exper. Biol. \& Med., 1952, 79, 372.

27. Henriques, F. C., Jr., Kistiakowsky, G. B., Margnetti, C., and Schneider, W. G., Radioactive studies. Analytical procedure for measurement of long-lived radioactive sulfur, $\mathrm{S}^{25}$, with a Lauritzen electroscope and comparison of electroscope with special Geiger counter. Ind. \& Eng. Chem. (Analyt. Ed.), 1946, 18, 349.

28. Walser, M., and Reid, A. F., To be published.

29. Roe, J. H., Epstein, J. H., and Goldstein, N. P., A photometric method for the determination of inulin in plasma and urine. J. Biol. Chem., 1949, 178, 839.

30. Power, M. H., and Wakefield, E. G., A volumetric benzidine method for the determination of inorganic and ethereal sulfate in serum. J. Biol. Chem., 1938, 123, 665.

31. Dziewiatkowski, D. D., On the utilization of exogenous sulfate sulfur by the rat in the formation of ethereal sulfates as indicated by the use of sodium sulfate labelled with radioactive sulfur. J. Biol. Chem., 1949, 178, 389.

32. Bjering, T., and Øllgaard, E., Studies in sulphate clearance. Acta. Med. Scandinav., 1939, 102, 55.

33. Cope, C. L., Inorganic sulphate excretion by the human kidney. J. Physiol., 1932, 76, 329.

34. Keith, N. M., Power, M. H., and Peterson, R. D., The renal excretion of sucrose, xylose, urea, and inorganic sulphates in normal man: comparison of simultaneous clearances. Am. J. Physiol., 1934, 108, 221.

35. Smith, H. W., The Kidney: Structure and Function in Health and Disease. Oxford Univ. Press, New York, 1951, p. 123.

36. Watchorn, E., and McCance, R. A., Inorganic constituents of the cerebrospinal fluid. VI. Sulphur. Biochem. J., 1935, 29, 2291.

37. Hayman, J. M., Jr., The excretion of inorganic sulphates. J. Clin. Invest., 1932, 11, 607.

38. Goudsmit, A., Jr., Power, M. H., and Bollman, J. L., The excretion of sulfates by the dog. Am. J. Physiol., 1939, 125, 506.

39. Gaudino, M., Schwartz, I. L., and Levitt, M. F., Inulin volume of distribution as a measure of extracellular fluid in dog and man. Proc. Soc. Exper. Biol. \& Med., 1948, 68, 507.

40. Edelman, I. S., Olney, J. M., James, A. H., Brooks, L., and Moore, F. D., Body composition: studies in the human being by the dilution principle. Science, 1952, 115, 447.

41. Walser, M., Seldin, D. W., and Grollman, A., Unpublished observations.

42. Harrison, H. E., Darrow, D. C., and Yannet, H., The total electrolyte content of animals and its probable relation to the distribution of body water. J. Biol. Chem., 1936, 113, 515. 
43. Weir, E. G., Determination of the total chloride content of animals following administration of sodium bromide. Am. J. Physiol., 1939, 127, 338.

44. Dunning, M. F., Steele, J. M., and Berger, E. Y., Measurement of total body chloride. Proc. Soc. Exper. Biol. \& Med., 1951, 77, 854.

45. Deane, N., Ziff, M., and Smith, H. W., The distribution of total body chloride in man. J. Clin. Invest., 1952, 31, 200.

46. Steele, J. M., Body water in man and its subdivisions. Bull. N. Y. Acad. Med., 1951, 27, 679.

47. Amberson, W. R., Nash, T. P., Mulder, A. G., and Binns, $D$., The relationship between tissue chloride and plasma chloride. Am. J. Physiol., 1938, 122, 224.

48. Hiatt, E. P., Extreme hypochloremia in dogs induced by nitrate administration. Am. J. Physiol., 1940, 129, 597.

49. Yannet, H., and Darrow, D. C., The effect of depletion of extracellular electrolytes on the chemical composition of skeletal muscle, liver, and cardiac muscle. J. Biol. Chem., 1940, 134, 721.

50. Mellors, R. C., Muntwyler, E., and Mautz, F. R., Electrolyte and water equilibria in the dog. IV. Electrolyte and water exchange between skeletal muscle, "available (thiocyanate) fluid," and plasma in acute and in prolonged dehydration. J. Biol. Chem., 1941, 140, 1xxxix.

51. Nichols, G., Jr., Nichols, N., Weil, W. B., and Wallace, W. M., The direct measurement of the extracellular phase of tissues. J. Clin. Invest., 1952, 31, 652.

52. Boyle, P. J., Conway, E. J., Kane, F., and O'Reilly, H. L., Volume of interfibre spaces in frog muscle and the calculation of concentrations in the fibre water. J. Physiol., 1941, 99, 401.
53. Mokotoff, R., Ross, G., and Leiter, L., The electrolyte content of skeletal muscle in congestive heart failure; a comparison of results with inulin and chloride as reference standards for extracellular water. J. Clin. Invest., 1952, 31, 291.

54. Wilde, W. S., The chloride equilibrium in muscle. Am. J. Physiol., 1945, 143, 666.

55. Conway, E. J., and Kane, F., Diffusion rates of anions and urea through tissues. Biochem. J., 1934, 28, 1769.

56. Behnke, A. R., Jr., Physiologic studies pertaining to deep sea diving and aviation, especially in relation to the fat content and composition of the body. Bull. N. Y. Acad. Med. (Harvey Lectures), 1942, 18, 561.

57. Pace, N., and Rathbun, E. N., Studies on body composition. III. The body water and chemically combined nitrogen content in relation to fat content. J. Biol. Chem., 1945, 158, 685.

58. Messinger, W. J., and Steele, J. M., Relationship of body specific gravity to body fat and water content. Proc. Soc. Exper. Biol. \& Med., 1949, 70, 316.

59. Osserman, E. F., Pitts, G. C., Welham, W. C., and Behnke, A. R., In vivo measurement of body fat and body water in a group of normal men. J. Applied Physiol., 1949-50, 2, 633.

60. Kraybill, H. F., Hankins, O. G., and Bitter, H. L., Body composition of cattle. I. Estimation of body fat from measurement in vivo of body water by use of antipyrine. J. Applied Physiol., 1950-51, 3, 681.

61. Hastings, A. B., The electrolytes of tissues and body fluids. The Harvey Lectures, 1940-41, series 36, 91. 